\title{
Postprandial blood glucose as a risk factor for cardiovascular disease in Type II diabetes: the epidemiological evidence
}

\author{
E. Bonora, M. Muggeo \\ Division of Endocrinology and Metabolic Disease, University of Verona Medical School, Verona, Italy
}

\begin{abstract}
That cardiovascular disease occurs more frequently in patients with Type II (non-insulin-dependent) diabetes mellitus has been recognized for a long time. However, the extent to which hyperglycaemia contributes to atherosclerosis and cardiovascular disease is still not clear. Epidemiological studies published in recent years suggest that postprandial blood glucose might be an independent risk factor of cardiovascular disease. The main results of these studies, which are reviewed in this article, are that subjects from the general population with mild to moderate hyperglycaemia, following oral glucose load, but not in the fasting state, showed an increased cardiovascular risk. Furthermore, the post-challenge as well as postprandial glucose concentrations of subjects with Type II diabetes were found to be directly associated
\end{abstract}

to incident cardiovascular disease independently of fasting glucose. Also, the correction of fasting hyperglycaemia or $\mathrm{HbA}_{1 \mathrm{c}}$ or both, disregarding the specific correction of postprandial hyperglycaemia was not found to significantly reduce the incidence of cardiovascular disease in patients with Type II diabetes. Finally, the strict control of both preprandial and postprandial hyperglycaemia yielded a substantial reduction of cardiovascular disease in Type II diabetes. Trials specifically designed to address this issue are needed to determine whether postprandial hyperglycaemia plays an independent and causative role in cardiovascular disease in patients with Type II diabetes. [Diabetologia (2001) 44: 2107-2114]

Keywords Type II diabetes, cardiovascular disease, fasting glucose, postprandial glucose, $\mathrm{HbA}_{1 \mathrm{c}}$.
Type II (non-insulin-dependent) diabetes mellitus is one of the most common metabolic disorders. Epidemiological studies carried out in European countries in the 1980 s showed that about $3 \%$ of the general population had Type II diabetes [1]. Because the number of subjects with the disease is increasing steadily in both affluent and developing countries, the number of people with diabetes in the world is predicted to double over the next 20 years [2]. The reasons for this increase include greater longevity

Corresponding author: E. Bonora, Endocrinologia e Malattie del Metabolismo, Ospedale Maggiore, Piazzale Stefani, 1, Verona, Italy, e-mail: enbonor@tin.it

Abbreviations: PPG, Postprandial plasma glucose; FPG, fasting plasma glucose; IPH, isolated post-challenge hyperglycaemia; ADA, American Diabetes Association and a change of life style habits leading to weight gain. In fact, age and overweight are among the major risk factors for Type II diabetes [3, 4]. It has been estimated that the costs for medical care related to the disease will steeply increase over the next decades [5]. The main part of medical costs generated by Type II diabetes are not related to pharmacological glucose control, but to treatment of chronic complications, namely nephropathy, retinopathy, neuropathy and accelerated atherosclerosis [5].

The main clinical manifestations of atherosclerosis, such as coronary heart disease (CHD), cerebrovascular disease and peripheral vascular disease afflict a remarkable proportion of patients with Type II diabetes [6]. Indeed, these patients have a mortality risk for coronary, cerebrovascular and peripheral vascular disease, which is twofold to tenfold higher 
than non-diabetic patients $[7,8]$. Not surprisingly, cardiovascular disease (CVD) is the leading cause of death among Type II diabetic subjects and accounts for $40-50 \%$ of all deaths [9].

Although Type II diabetes is frequently associated with other cardiovascular risk factors, such as dyslipidaemia and hypertension [10,11], there is an increased cardiovascular risk in diabetic patients which is not explained by these factors and is thought to be related to hyperglycaemia [12]. This is one of the main reasons, besides prevention, delay, or arrest of microangiopathic complications, why the correction of hyperglycaemia is the primary aim in diabetes care.

In Type II diabetes fasting plasma glucose (FPG) and glycated haemoglobin $\left(\mathrm{HbA}_{1 \mathrm{c}}\right)$ are the main parameters of glucose metabolism which are used to monitor and control hyperglycaemia [13]. More recently, particular emphasis has been given to nonfasting, mainly postprandial plasma glucose (PPG) as a parameter to include in the metabolic assessment of Type II diabetic patients [14]. This new perspective originated from the results of several epidemiological observational studies surveying both the general population and the diabetic population, as well as from the discussion and interpretation of the results of intervention trials carried out in diabetic patients.

Evidence that PPG is an independent risk factor in diabetes comes from observational studies focusing on diabetic patients. Unfortunately, such studies are still sparse. A detrimental role of postprandial hyperglycaemia in diabetes can also be inferred from some intervention trials carried out in diabetic patients. These studies documented that the correction of fasting hyperglycaemia only, disregarding PPG levels, had no or only limited beneficial effects on CVD. Moreover, numerous studies examining samples from the general population, including patients with variable degrees of glucose tolerance, provide valuable support to the idea that postprandial hyperglycaemia is harmful. These studies are based on the assessment of glucose concentrations during an oral glucose tolerance test (OGTT), which might be considered as a surrogate of PPG. However, the extent to which post-challenge plasma glucose does reflect glucose concentration after a mixed meal is not well understood, as few studies have addressed this issue. Of course, the ingestion of the precursors of different energy substrates like proteins, lipids and complex carbohydrates is not equivalent to the ingestion of dextrose as in the OGTT. Nevertheless, a strong correlation $(r>0.90)$ was found between glucose peaks following mixed meal and oral glucose load [15]. Moreover, the OGTT is not easily reproducible [16], and for this reason the WHO recommends two tests before a clinical diagnosis of diabetes is established [17]. On the other hand the repetition of the OGTT in epidemiological studies is not feasible and the re- sults of a single test is generally accepted. In this regard, it should be emphasized that the standard OGTT has been used for a long time to categorize individuals according to glucose tolerance and to infer approximately the magnitude of their plasma glucose excursions occurring with meals in the everyday life.

\section{Impaired glucose tolerance and cardiovascular disease}

Several studies examined the association between glucose concentrations following oral glucose load and cardiovascular disease in the general population. A number of these studies targeted subjects with impaired glucose tolerance (IGT), i.e. those with nondiabetic fasting glucose concentrations $(<7 \mathrm{mmol} / \mathrm{l})$ but a moderately higher glycaemic response during an OGTT, with plasma glucose concentrations ranging from $7.8-11.0 \mathrm{mmol} / \mathrm{l} 2 \mathrm{~h}$ after the glucose load [17]. As already stated, it is assumed that these patients have mildly higher glycaemia in the postprandial state. Despite only mild abnormality of glucose metabolism, these patients have an increased cardiovascular risk.

One of the pioneer papers focusing on CVD in subjects with high glucose concentrations during OGTT or with IGT was the Whitehall Study, carried out in England [18]. In this study 18403 individuals aged 40 to 60 years were followed for 7.5 years. The CHD mortality in those with a high glucose response to a $50 \mathrm{~g}$ oral glucose load ( $>95^{\text {th }}$ centile) was twice as high as in those with a normal glucose response. Similar results were found in the Paris Prospective Study (19), in which 7038 subjects aged 43 to 54 years were followed up for 10 years, and in the Helsinki Policemen Study, involving 1059 men aged 30-59 years followed for 10 years (20). Similar results were obtained in more recent surveys. In the Funagata Diabetes Study, surveying 2534 subjects aged over 40 years of age followed for 7 years, the hazard ratio of IGT to NGT in terms of CVD death was 2.22 [21]. In the Cardiovascular Health Study, in which 4515 subjects aged $>65$ years were followed for 8 years, the risk associated with IGT was lower (1.22), but still significantly increased after adjusting for classic risk factors [22].

Atherosclerosis is the anatomical lesion underlying clinical manifestations of CVD. We have recently reported that the risk of developing carotid stenosis during a 5-year follow-up of 888 subjects aged 40-79 years was threefold higher in those with IGT than in those with NGT [23]. Consistent results were observed in the Hoorn Study [24], where carotid blood flow was measured with Doppler technique, and in studies measuring carotid intimal-media thickness as a surrogate index of atherosclerosis [25, 26]. 


\section{Diabetic 0GTT, isolated post-challenge hyperglycaemia and cardiovascular disease}

It is well known that people who have normal $(<6.1 \mathrm{mmol} / \mathrm{l})$ or only slightly higher fasting glucose (6.1-6.9 mmol/1), but a remarkable increase in plasma glucose following an OGTT and, conceivably, after meals, do exist. In these individuals, in whom plasma glucose concentrations exceed $11.1 \mathrm{mmol} / \mathrm{l} 2 \mathrm{~h}$ after glucose load, the diagnosis of diabetes is fully established according to standard criteria [17]. These patients belong to a sort of subcategory of diabetes (isolated post-challenge hyperglycaemia or IPH), which is particularly intriguing, as it can be identified only by OGTT, a diagnostic tool which is not very widespread in clinical practice. For this reason the American Diabetes Association (ADA) recently decided to base the diagnosis of diabetes essentially on FPG, and to establish a new category of altered glycaemia termed "Impaired Fasting Glucose" [27]. This decision has been challenged [28-30] and the OGTT remains one of the diagnostic procedures recommended by the WHO [17] because this special type of diabetic patient, who generally progress to overt diabetes with definite fasting hyperglycaemia, should be identified, as they have an increased risk of chronic diabetic complications [31]. Indeed, the high prevalence of cardiovascular disease found at the time when Type II diabetes is first diagnosed [32] is thought to be the result of both several years of undetected mild to moderate hyperglycaemia, mainly in the postprandial state [33], and the clustering of several cardiovascular risk factors in the prediabetic phase [34].

Over the last few years several studies have clearly indicated that patients with a diabetic 2-h glucose concentration $(\geq 11 \mathrm{mmol} / \mathrm{l})$ and mostly with IPH, have an increased risk of developing atherosclerosis and clinical manifestations of CVD. In the Honolulu Heart Program (35), studying 8006 Japanese-American men aged 45-68 years, followed for 23 years, it was found that the risk of CHD was significantly increased in subjects with a diabetic OGTT compared with subjects with NGT. The relative risk was 2.01 after adjusting for other risk factors. The Chicago Heart Association Detection Project In Industry Study [36] enrolled approximately 12000 men aged from 35 to 64 years. After 22 years of follow-up, a multivariate analysis showed that exaggerated $1-\mathrm{h}$ post-load plasma glucose response was an independent predictor of CVD mortality (RR 1.18). In the Rancho Bernardo Study [37] 1858 subjects with FPG $<7.0 \mathrm{mmol} / 1$ (not diabetes according to 1997 ADA criteria) were recruited. After a 7-year followup, women (but not men) with IPH displayed an increased risk of CVD death, independently of other risk factors (RR 2.6). In the Paris Prospective Study [38] the 23-year follow-up of 7038 men aged
43-54 years showed that those with a diabetic OGTT had a relative risk of CHD of 1.31, after adjustment for other risk factors. In studies carried out in the Mauritius, Fiji and Nauru Islands [39], surveying a total of 9179 people who were followed for 5 to 12 years, a mortality risk for CVD of 2.6 was found in IPH, after adjusting for other risk factors. The Hoorn Study [40], surveyed 2363 Dutch people aged 50-75 years. After adjusting for classic risk factors, it was found that the relative risk for CVD mortality in subjects with a diabetic OGTT was 2.22.

The study providing the most convincing evidence of the increased cardiovascular risk related to IPH is the DECODE (Diabetes Epidemiology: Collaborative analysis Of Diagnostic criteria in Europe). In this project [41] data from more than 25000 subjects surveyed in different European epidemiologic studies were pooled. All-cause and specific cause mortality during a mean follow-up of 7.3 years (180000 person-years) were assessed after stratification according to fasting (1997 ADA criteria) and post-challenge (1985 WHO criteria) plasma glucose. When using the ADA criteria [17], subjects with previously undiagnosed diabetes (FPG $\geq 7.0 \mathrm{mmol} / \mathrm{l})$, displayed a significant increase in mortality (odds ratio 1.81) compared with non-diabetic people (FPG $<6.1 \mathrm{mmol} / \mathrm{l})$. However, the risk was increased only when plasma glucose $2 \mathrm{~h}$ after the glucose load was in the IGT range $(7.8-11.0 \mathrm{mmol} / \mathrm{l})$ or, to a greater extent, in the diabetic range $(\geq 11.1 \mathrm{mmol} / \mathrm{l})$. When subjects were stratified according to 1985 WHO criteria [42], subjects with 2-h OGTT plasma glucose $\geq 11.1 \mathrm{mmol} / \mathrm{l}$ had a relative risk of mortality twofold higher than subjects with NGT, with no significant differences across categories of fasting plasma glucose $(<6.1$, $6.1-6.9, \geq 7.0 \mathrm{mmol} / \mathrm{l})$. In other words, within each FPG category, the mortality risk increased linearly across categories of post-OGTT plasma glucose, whereas within each category of 2-h OGTT $(<7.8$, $7.8-11 \geq 11.1 \mathrm{mmol} / \mathrm{l})$ the mortality risk did not increase across categories of FPG. The death risk associated with IPH was well evident in older subjects from the DECODE: the hazard ratio was 1.60 (C.I. 1.1-2.3) in men and women over 60 years of age with IPH than in age-matched subjects with fasting glucose of less than 7.0 and 2 -h glucose $\leq 11.1 \mathrm{mmol} / \mathrm{l}$ [43].

A more recent analysis of the DECODE data focusing on CVD (268811 person-years) showed that, after adjusting for possible confounders, and with FPG and 2-h glucose in the same model, the relative risk of CVD was not significantly increased in subjects with a FPG of 7.0 of more than in those with a FPG of less than $6.1 \mathrm{mmol} / \mathrm{l}$ (RR $1.20,95 \%$-CI $0.88-1.64, p=\mathrm{NS})$. On the contrary, the risk of CVD mortality in subjects with 2-h OGTT plasma glucose of $11.1 \mathrm{mmol} / 1$ or more was $1.40(1.02-1.92$, $p<0.005)$ compared with those with 2-h OGTT 
$<7.8 \mathrm{mmol} / \mathrm{l}$. Therefore, FPG was not an independent predictor of CVD mortality when the multivariate analysis included both FPG and post-challenge PG. In this analysis, only the latter turned out to be an independent predictor of CVD mortality [44].

In full agreement with studies on clinical CVD, studies assessing asymptomatic carotid atherosclerosis by echo-duplex scanning documented an increased risk of arterial abnormalities in subjects with IPH [45].

Overall, there is a convincing epidemiological evidence supporting the conclusion that, in spite of normal fasting glycaemia, an exaggerated increase in plasma glucose $2 \mathrm{~h}$ after the glucose load and, by extrapolation, after meals, is associated with an increased risk of atherosclerosis and CVD. This conclusion suggests that individuals with IPH should be identified and their metabolic abnormality corrected with medications capable of controlling excessive increases in blood glucose after meals.

\section{Postprandial glucose and cardiovascular risk in diabetes mellitus}

As previously mentioned, few studies specifically evaluate the risk associated with postprandial hyperglycaemia in Type II diabetes. The Diabetes Intervention Study [46], focusing on myocardial infarction and total mortality (mainly for CVD), examined 1139 newly diagnosed Type II diabetic patients, 30-55 years of age, who were followed for 11 years. In the univariate analysis 1-h post-breakfast blood glucose, but not FPG, was associated with higher rates of myocardial infarction and death. In particular, the frequency of myocardial infarction in subjects with PPG greater than $10 \mathrm{mmol} / \mathrm{l}$ was $40 \%$ higher than in patients with PPG of less than $8 \mathrm{mmol} / \mathrm{l}$. In a multivariate regression analysis PPG, but not FPG, was an independent predictor of total mortality. This study is particularly important as, to our knowledge, it is the only one in the literature in which postprandial rather than post-challenge glucose was assessed. In a 10-year prospective study carried out in 1745 diabetic Pima Indians aged 15-88 years, 2-h OGTT plasma glucose, which could be taken to represent postprandial hyperglycaemia, was independently associated with CVD disease: a $5.6 \mathrm{mmol} / \mathrm{l}$ increase resulted in a $20 \%$ increase in the risk [47]. Data from 229 Type II diabetic patients aged $65-74$ years followed for 3.5 years in Finland might seem at variance with these results [48]. In this study only $\mathrm{HbA}_{1 \mathrm{c}}$, but not 2-h OGTT and fasting plasma glucose, were independent predictors of CHD. However, as $\mathrm{HbA}_{1 \mathrm{c}}$ is a function of both FPG and PPG, a specific deleterious effect of postprandial hyperglycaemia might not be detectable when using $\mathrm{HbA}_{1 \mathrm{c}}$ as a parameter of glucose control. In the same cohort it was observed that
FPG was a stronger predictor of stroke than 2-h OGTT plasma glucose [49]. In the already mentioned DECODE Study, it was observed that within diabetic subjects (known and previously undiagnosed with FPG $\geq 7 \mathrm{mmol} / \mathrm{l})$ those with the higher glucose concentrations following OGTT had the highest risk of CVD mortality [44]. In a cohort of 1121 patients with Type II diabetes followed for several years (mean follow-up 52 months) who had plasma glucose assessment $2 \mathrm{~h}$ after breakfast or lunch, we found that both FPG and PPG were able to predict subsequent prevalent and incident cases of CVD after adjusting for other risk factors (Bonora et al, unpublished data).

These findings support the conclusion that postprandial hyperglycaemia in diabetic subjects is a more powerful marker of CVD risk than fasting hyperglycaemia. Several experimental studies [50-59] provide a plausible pathophysiological explanation for epidemiological data and give strength to the idea that postprandial hyperglycaemia is harmful. However, further studies focusing on the association of postprandial glucose with CVD in Type II diabetes are needed to confirm these conclusions.

\section{Intervention studies and cardiovascular disease in Type II diabetes}

A number of intervention studies were carried out to study whether reducing blood glucose results in a better outcome in Type II diabetes. The first of these studies was the UGDP, which followed approximately 1000 recently-diagnosed patients for 12.5 years, during which they were treated with diet, oral agents or fixed or variable doses of insulin [60]. In all arms of the study, the prevention of diabetes symptoms was the therapeutic goal, but in patients undergoing variable insulin treatment, the daily dose of ultralente insulin was to be increased by at least 2 units per day if a patient had a fasting glucose value of $6.1 \mathrm{mmol} / \mathrm{l}$ or a 1-h OGTT $(50 \mathrm{~g})$ value of $11.7 \mathrm{mmol} / \mathrm{l}$ or more. Patients undergoing this more personalized form of insulin treatment had significantly lower fasting glucose concentrations throughout the study than the other groups (on average $2.5 \mathrm{mmol} / \mathrm{l}$ ). Nevertheless, the study failed to document any advantage in this sustained reduction of blood glucose in terms of cardiovascular events.

More recently a collaborative study of the U.S. Veteran Affairs (VA CSDM) was planned. This project focused on Type II diabetic patients with poor control, part of whom were switched to intensive control with multiple step therapy with oral agents and insulin. The goal was to normalize $\mathrm{HbA}_{1 \mathrm{c}}$ and FPG $(<6.4 \mathrm{mmol} / \mathrm{l})$ and control preprandial $(<7.2 \mathrm{mmol} / \mathrm{l})$, but not postprandial blood glucose concentrations. In a pilot study of the project [61], de- 
spite a clear-cut difference in FPG $(\sim 5 \mathrm{mmol} / \mathrm{l})$ and $\mathrm{HbA}_{1 \mathrm{c}}(\sim 2 \%)$ in patients undergoing more intensive treatment compared with the others, no significant advantage in terms of cardiovascular events was found. On the contrary, patients with lower glucose concentrations tended to have more cardiovascular events.

The UK Prospective Diabetes Study (UKPDS) is the largest intervention study on Type II diabetes $[62,63]$. It was designed to evaluate the effect of intensive blood glucose control, achieved by different approaches, on the risk of macrovascular and microvascular complications. A total of 3867 newly diagnosed Type II diabetic patients with FPG concentrations ranging from 6.0 to $15.0 \mathrm{mmol} / \mathrm{l}$ at the end of a 3-month diet period were randomised to conventional treatment $(n=1138)$ or to receive intensive treatment with sulphonylureas (chlorpropamide, glibenclamide, glipizide, $n=1573$ ) or insulin $(n=1156)$, the aim being to keep FPG below $6.0 \mathrm{mmol} / \mathrm{l}$. In the former group medications (oral agents or insulin) were allowed only when dietary measures failed to maintain FPG at $15 \mathrm{mmol} / \mathrm{l}$ or more or when symptoms attributable to hyperglycaemia appeared. The UKPDS also examined overweight subjects $(n=1794)$ who were randomised to conventional treatment $(n=411)$, or to intensive treatment with metformin $(n=342)$, chlorpropamide $(n=265), \quad$ glibenclamide $\quad(n=277) \quad$ or insulin $(n=409)$. Three aggregate endpoints were defined to reveal differences in treatment outcomes: 1) "any diabetes-related endpoint" (sudden death, death from hyperglycaemia or hypoglycaemia, fatal or non-fatal myocardial infarction, angina, heart failure, stroke, renal failure, amputation, vitreous hemorrhage, retinopathy needing photocoagulation, unilateral blindness, cataract extraction); 2) "diabetes-related death" (myocardial infarction, stroke, peripheral vascular disease, renal disease, hyper- or hypoglycaemia, sudden death); 3 ) "all-cause mortality". During a mean follow-up of 10 years, patients on intensive treatment achieved a $\mathrm{HbA}_{1 \mathrm{c}}$ mean value about $1 \%$ lower than that of patients on conventional treatment $(7.0 \%$ vs $7.9 \%)$. Furthermore, overweight patients treated with metformin had a better metabolic control than those on conventional treatment $\left(\mathrm{HbA}_{1 \mathrm{c}} 7.4 \%\right.$ vs $\left.8.0 \%\right)$. Compared with conventional treatment, intensive treatment significantly reduced any diabetes-related endpoint by $12 \%$, mainly owing to the reduction of microvascular complications $(-25 \%)$. On the contrary, cardiovascular death, diabetes-related death and all-cause mortality were not significantly reduced by intensive treatment. Indeed, the study showed a $16 \%$ reduction of myocardial infarction in subjects intensively treated with sulphonylureas or insulin and this reduction was close to statistical significance $(p=0.056)$. However, the incidence of strokes tended to be higher in the intensive treatment group, so overall cardiovascular disease incidence was not different in subjects undergoing intensive and conventional treatment. Of note, among overweight patients, only treatment with metformin resulted in a significant reduction of myocardial infarction $(-39 \%)$, diabetes-related death $(-42 \%)$ and all-cause mortality $(-36 \%)$.

The results of these intervention studies in Type II diabetes yielded rather disappointing results, as the reduction of FPG and $\mathrm{HbA}_{1 \mathrm{c}}$ did not achieve a significant decrease in cardiovascular complications, possibly the major burden of Type II diabetes. However, in these trials the therapeutic focus was on FPG, preprandial glucose or $\mathrm{HbA}_{1 \mathrm{c}}$ or both. In these studies no attention was paid to control plasma glucose concentrations in the postprandial period, which contribute to $\mathrm{HbA}_{1 \mathrm{c}}$ but to a lesser extent than fasting or interprandial glucose concentrations, as recently stated by a Consensus Panel of the American Diabetes Association [64]. Accordingly, we found that the coefficients of correlation of $\mathrm{HbA}_{1 \mathrm{c}}$ with fasting glucose and post-breakfast glucose were 0.750 and 0.657 , respectively, in 493 patients attending the Verona Diabetes Clinic in year 2000 who had an assessment of fasting plasma glucose, post-breakfast plasma glucose and $\mathrm{HbA}_{1 \mathrm{c}}$ on the same day. These results were confirmed in out-patients performing home blood glucose monitoring and whose mean preprandial and postprandial glucose concentrations over a 2 month period were plotted against $\mathrm{HbA}_{1 \mathrm{c}}$ (Bonora et al., submitted manuscript).

The results obtained in the above-mentioned studies were substantially different from those of the DCCT [65], where Type I diabetic subjects in the intensive treatment group had insulin treatment aimed at controlling both preprandial and postprandial glucose levels. Although the pathogenesis of CVD in Type I diabetes is thought to be different from the pathogenesis of CVD in Type II diabetes, it is interesting to note that the reduction in cardiovascular events in the DCCT subjects on intensive treatment, although not statistically significant due to low statistical power, was $41 \%$ [65]. Thus, the failure to obtain significant results in terms of CVD in the UGDP, in the VA CSDM and in the UKPDS studies could be a consequence of disregarding postprandial hyperglycaemia, as several observational and experimental studies suggest that this parameter might be an independent risk factor for CVD. In this regard, the results of the Kumamoto study [66], which followed 110 Type II diabetic subjects for 8 years are interesting. This study, with an experimental design that was similar to the DCCT, aimed to control glucose levels throughout the day in subjects belonging to the intensive treatment group. In this study, CVD results were better than in the UKPDS and other intervention studies. Indeed, although the power of the study did not permit the achievement of statistical significance, 
a $56 \%$ reduction in CVD was observed in patients undergoing intensive insulin treatment, resulting in the reduction of both preprandial and postprandial glucose levels. Also the DIGAMI Study [67], an intervention study on 620 Type II diabetic patients suffering from acute myocardial infarction, documented a better CVD outcome when metabolic control by intensive insulin treatment was extended to postprandial glycaemia.

Of course intensive insulin treatment, as used in the Kumamoto Study or the DIGAMI Study, is not to be recommended for all Type II diabetic subjects $[13,68]$ in order to accomplish strict control of both fasting and postprandial glucose levels. However, the therapeutic plan of diabetes should not focus solely on FPG and $\mathrm{HbA}_{1 \mathrm{c}}$, disregarding non fasting and especially postprandial glucose. In other words, the goal of diabetes care should be the attainment of a more physiological glucose profile, and not only satisfactory levels of FPG or $\mathrm{HbA}_{1}$. In this regard, the diabetes care provider might consider the use of oral hypoglycaemic agents that are specifically effective on postprandial hyperglycaemia, like new non-sulphonylureic insulin secretagogues [69, 70]. These drugs have the specific ability to improve or even normalize the abnormal first-phase insulin secretion of Type II diabetic patients, thereby blunting the exaggerated glucose increase occurring after meals. Ongoing studies will clarify whether this effect actually results in a better CVD outcome in Type II diabetes.

\section{Conclusions}

It is thought that there will be a major epidemic of Type II diabetes in the near future. The disease is burdened by high costs mainly due to chronic complications. Among the latter, CVD is the most common. A large body of direct and indirect epidemiological evidence, as well as of experimental data, supports the hypothesis that the prevention of CVD in Type II diabetes, and perhaps in prediabetic states as IGT, could also be accomplished by means of the correction of postprandial hyperglycaemia. This hypothesis needs to be confirmed by trials comparing subjects undergoing a strict control of fasting (and preprandial) glucose concentrations only and subjects undergoing a strict control throughout the day, including the postprandial phase. Such studies are underway but their results will not be available for several years. In the meanwhile, it would be reasonable and prudent to implement for Type II diabetic patients the same strategies in use as for Type I diabetic patients, which include the control of both fasting and postprandial hyperglycaemia. These strategies are inevitably dependent upon home blood glucose monitoring, with assessment of glucose concentrations at different times of the day, including the postprandial period.
The frequency of home monitoring of both preprandial and postprandial blood glucose levels should be tailored on the single patients, taking into account several factors including age, individual glucose targets, type of treatment, degree of current metabolic control, co-morbidity and intercurrent illnesses. In the typical patient treated with oral agents, a single blood glucose assessment each day or on alternate days, changing the time of assessment day by day (pre-breakfast, post-breakfast, pre-lunch, post-lunch and so on), would be sufficient to supply the diabetes care provider with a comprehensive information as to whether glucose targets are met.

Sources. This review is based on the relevant literature published in the English language during the period 1970-2001 and seminal prior contributions. The sources available to the authors were integrated with sources identified through PubMed searches for "plasma glucose and cardiovascular disease", "glucose control and cardiovascular disease", "postprandial glucose and cardiovascular disease", "OGTT and cardiovascular disease".

\section{References}

1. Muggeo M, Verlato G, Bonora E et al. (1995) The Verona diabetes study: a population-based survey on known diabetes mellitus prevalence and 5-year all-cause mortality. Diabetologia 38: 318-325

2. King H, Aubert RE, Herman WH (1998) Global burden of diabetes, 1995-2025. Prevalence, numerical estimates, and projections. Diabetes Care 21: 1414-1431

3. Harris MI, Hadden WC, Knowler WC, Bennett PH (1987) Prevalence of diabetes and impaired glucose tolerance and plasma glucose levels in the U.S. population aged 20-74 years. Diabetes 36: 523-534

4. Knowler WC, Pettitt DJ, Savage PJ, Bennett PH (1981) Diabetes incidence in Pima Indians: contribution of obesity and parental diabetes. Am J Epidemiol 113: 144-156

5. American Diabetes Association (1998) Economic consequences of diabetes mellitus in the U.S. in 1997. Diabetes Care 21: 296-309

6. Laakso M (1999) Hyperglycemia and cardiovascular disease in type 2 diabetes. Diabetes 48: 937-942

7. Stamler J, Vaccaro O, Neaton JD, Wentworth D for the Multiple Risk Factor Intervention Trial Research Group (1993) Diabetes, other risk factors, and 12-yr cardiovascular mortality for men screened in the Multiple Risk Factor Intervention Trial. Diabetes Care 16: 434-444

8. Manson JE, Colditz GA, Stampfer MJ et al. (1991) A prospective study of maturity-onset diabetes mellitus and risk of coronary heart disease and stroke in women. Arch Intern Med 151: 1141-1147

9. De Marco R, Locatelli F, Zoppini G, Verlato G, Bonora E, Muggeo M (1999) Cause-specific mortality in type 2 diabetes. Diabetes Care 22: 756-761

10. UK Prospective Diabetes Study Group (1997) UK Prospective Diabetes Study 27. Plasma lipids and lipoproteins at diagnosis of NIDDM by age and sex. Diabetes Care 20: 1683-1687 
11. The Hypertension in Diabetes Study Group (1993) Hypertension in Diabetes Study (HDS). I. Prevalence of hypertension in newly presenting type 2 diabetic patients and the association with risk factors for cardiovascular and diabetic complications. J Hypertens 11: 309-317

12. Bierman EL (1992) Atherogenesis in diabetes. Arterioscler Thromb 12: 647-656

13. American Diabetes Association (2001) Standards of care for patients with diabetes mellitus (Position Statement). Diabetes Care 24 [Suppl 1]: S33-S43

14. Muggeo M, Bolli G, Bompiani G et el. (2000) Glycemic control and cardiovascualar diseases in type 2 diabetes mellitus. Beyond fasting glycemia and glycosylated hemoglobin (Consensus Document). Diabetes Nutr Metab 13: 182-185

15. Wolever TMS, Chiasson JL, Csima A et al. (1998) Variation of postprandial plasma glucose, palatability and symptoms associated with a standardized mixed test meal versus $75 \mathrm{~g}$ oral glucose. Diabetes Care 21: 336-340

16. Mooy JM, Gootenhuis PA, de Vries H et al. (1996) Intraindividual variation of glucose, specific insulin and proinsulin concentrations measured by two oral glucose tolerance tests in general Caucasians population: the Hoorn Study. Diabetologia 39: 298-305

17. World Health Organization (1999) Definition, Diagnosis and Classification of Diabetes Mellitus and its Complications: Report of a WHO Consultation. Part I: Diagnosis and Classification of Diabetes Mellitus. World Health Organization, Geneva

18. Fuller JH, Shipley MJ, Rose G, Jarrett RJ, Keen H (1980) Coronary heart disease risk and impaired glucose tolerance: the Whitehall Study. Lancet i: $1373-1376$

19. Fontbonne A, Eschwege E, Cambien F et al. (1989) Hypertriglyceridemia as a risk factor of coronary heart disease mortality in subjects with impaired glucose tolerance or diabetes. Results from the 11-year follow-up of the Paris Prospective Study. Diabetologia 32: 300-304

20. Pyorala K (1979) Relationship of glucose tolerance and plasma insulin to the incidence of coronary heart disease: results from two population studies in Finland. Diabetes Care 2: 131-141

21. Tominaga M, Eguchi H, Manaka H, Igarashi K, Kato T, Seikikawa A (1999) Impaired glucose tolerance is a risk factor for cardiovascular disease, but not impaired fasting glucose. The Funagata Diabetes Study. Diabetes Care 22: 920-924

22. Barzilay JI, Spiekerman CF, Wahl PW et al. (1999) Cardiovascular disease in older adults with glucose disorders: comparison of the American Diabetes Association criteria for diabetes mellitus with WHO criteria. Lancet 354: $622-625$

23. Bonora E, Kiechl S, Oberhollenzer F, Egger G, Bonadonna RC, Muggeo M (2000) Impaired glucose tolerance, Type II diabetes mellitus and carotid artherosclerosis. Prospective results from the Bruneck Study. Diabetologia 43: 156-164

24. Beks PHJ, Mackaay AJC, de Vries H, de Neeling JND, Bouter LM, Heine RJ (1997) Carotid artery stenosis is related to blood glucose level in an elderly Caucasian population: the Hoorn Study. Diabetologia 40: 290-298

25. O'Leary DH, Polak JF, Kronmal RA et al. (1992) Distribution. and correlates of sonographically detected carotid artery disease in the Cardiovascular Health Study. Stroke 23: 1752-1760

26. Yamasaki Y, Kawamori R, Matsushima H et al. (1995) Asymptomatic hyperglycemia is associated with increased intimal plus medial thickness of the carotid artery. Diabetologia 38: $585-591$
27. American Diabetes Association (1999) Report of the Expert Committee on the Diagnosis and Classification of Diabetes Mellitus. Diabetes Care 22: S5-S19

28. The DECODE Study Group on behalf of the European Diabetes Epidemiology Study Group (1998) Will new diagnostic criteria for diabetes mellitus change phenotype of patients with diabetes? Reanalysis of European epidemiological data. BMJ 317: 371-375

29. The DECODE Study Group on behalf of the European Diabetes Epidemiology Group (1999) Is fasting glucose sufficient to define diabetes? Epidemiological data from 20 European studies. Diabetologia 42: 647-654

30. Qiao Q, Nakagami T, Tuomilehto J et al. (2000) Comparison of the fasting and the 2-h glucose criteria for diabetes in different Asian cohorts. Diabetologia 43: 1470-1475

31. McCance DR, Hanson RL, Charles MA, Jacobsson LTH, Pettitt DJ, Bennett PH, Knowler WC (1994) Comparison of tests for glycated hemoglobin and fasting and 2-hour plasma glucose concentrations as diagnostic methods for diabetes. BMJ 308: 1323-1328

32. UKPDS Group (1990) UK Prospective Diabetes Study 6. Complications in newly diagnosed type 2 diabetic patients and their association with different clinical and biochemical risk factors. Diabetes Res 13: 1-11

33. Muggeo M (1998) Accelerated complications in type 2 diabetes mellitus: the need for greater awareness and earlier detection. Diabet Med 15 [Suppl 4]: S60-S62

34. Haffner SM, Stern MP, Hazuda HP, Mitchell BD, Patterson JK (1990) Cardiovascular risk factors in confirmed prediabetic individuals. Does the clock for coronary heart disease start ticking before the onset of clinical diabetes? JAMA 263: 2934

35. Rodriguez BL, Lau N, Burchfield CM et al. (1999) Glucose intolerance and 23-year risk of coronary heart disease and total mortality. The Honolulu Heart Program. Diabetes Care 22: 1262-1265

36. Lowe LP, Liu K, Greenland P, Metzger BE, Dyer AR, Stamler J (1997) Diabetes, asymptomatic hyperglycemia, and 22-year mortality in black and white men: the Chicago Heart Association Detection Project in Industry Study. Diabetes Care 20: 163-169

37. Barrett Connor E, Ferrara A (1998) Isolated postchallange hyperglycemia and the risk of fatal cardiovascular disease in older women and men. The Rancho Bernardo Study. Diabetes Care 21: 1236-1239

38. Balkau B, Bertrais S, Ducimetiere P, Eschwege E (1999) Is there a glycemic threshold for mortality risk? Diabetes Care 22: 696-699

39. Shaw JE, Hodge AM, de Courten M, Chitson P, Zimmet PZ (1999) Isolated post-challenge hyperglycemia confirmed as a risk factor for mortality. Diabetologia 42 : 1050-1054

40. De Vegt F, Dekker JM, Ruhe HG et al. (1999) Hyperglycemia is associated with all-cause and cardiovascular mortality in the Hoorn population: the Hoorn Study. Diabetologia 42: 926-931

41. The DECODE study group on behalf of the European Diabetes Epidemiology Group (1999) Glucose tolerance and mortality: comparison of WHO and American Diabetes Association diagnostic criteria. Lancet 354: 617-621

42. World Health Organization (1985) Impaired glucose tolerance and diabetes. WHO criteria Technical Report Series No 727, WHO, Geneva

43. The DECODE study group on behalf of the European Diabetes Epidemiology Group (1999) Consequences of the new diagnostic criteria for diabetes in older men and women. Diabetes Care 22: 1667-1671 
44. The DECODE study group on behalf of the European Diabetes Epidemiology Group (2001) Glucose tolerance and cardiovascular mortality. Comparison of fasting and 2-h diagnostic criteria. Arch Intern Med 161: 397-404

45. Hanefeld M, Koehler C, Schaper F, Fuecker K, Henkel E, Temelkova-Kurktschiev T (1999) Postprandial plasma glucose is an independent risk factor for increased carotid intima-media thickness in non-diabetic individuals. Atherosclerosis 144: 229-235

46. Hanefeld M, Fischer S, Julius U et al. (1996) Risk factors for myocardial infarction and death in newly detected NIDDM: the Diabetes Intervention Study, 11-year followup. Diabetologia 39: 1577-1583

47. Sievers ML, Bennett P, Nelson RG (1999) Effect of glycemia on mortality in Pima Indians with type 2 diabetes. Diabetes 48: 896-902

48. Kuusisto J, Mykkanen L, Pyorala K, Laakso M (1994) NIDDM and its metabolic control predict coronary heart disease in elderly subjects. Diabetes 43: 960-967

49. Kuusisto J, Mykkanen L, Pyorala K, Laakso M (1994) Noninsulin-dependent diabetes and its metabolic control are important predictors of stroke in elderly subjects. Stroke 25: $1157-1164$

50. Jones RL, Peterson CM (1979) Reduced fibrinogen survival in diabetes mellitus. A reversible phenomenon. J Clin Invest 63: 485-493

51. Giugliano D, Ceriello A, Paolisso G (1996) Oxidative stress and diabetic vascular complications. Diabetes Care 19: 257-267

52. Pirags V, Assert R, Haupt K, Schatz H, Pfeiffer A (1996) Activation of human platelet protein kinase C-beta 2 in vivo in response to acute hyperglycemia. Exp Clin Endocrinol Diabetes 104: 431-440

53. Giugliano D, Marfella R, Coppola L et al. (1997) Vascular effects of acute hyperglycemia in humans are reversed by L-arginine: evidence for reduced availability of nitric oxide during hyperglycemia. Circulation 95: 1783-1790

54. Williams SB, Goldfine AB, Timimi FK, Ting HH, Roddy M-A, Simonson DC, Creager MA (1998) Acute hyperglycemia attenuates endothelium-dependent vasodilatation in humans in vivo. Circulation 97: 1695-1701

55. Ceriello A (1998) The emerging role of postprandial hyperglycemic spikes in the pathogenesis of diabetic complications. Diabet Med 15: 188-193

56. Akbari CM, Saouaf R, Barnhill DF, Newman PA, LoGerfo FW, Veves A (1998) Endothelium-dependent vasodilatation is impaired in both microcirculation and macrocirculation during acute hyperglycemia. J Vasc Surg 28: 687-694

57. Baynes JW, Thorpe SR (1999) Role of oxidative stress in diabetic complications: a new perspective on an old paradigm. Diabetes 48: 1-9
58. Marfella R, Esposito K, Giunta R et al. (2000) Circulating adhesion molecules in humans: role of hyperglyaemia and hyperinsulinemia. Circulation 101: 2247-2251

59. Ceriello A (2000) The postprandial state and cardiovascular disease: relevance to diabetes mellitus. Diabetes Metab Res Rev 16: 125-132

60. University Group Diabetes Program (1982) Effects of hypoglycaemic agents on vascular complications in patients with adult-onset diabetes. VIII. Evaluation of insulin therapy. Final report. Diabetes 31 [Suppl 5]: 1-26

61. Abraira C, Colwell JA, Nuttall FQ et al. (1997) Cardiovascular events and correlates in the Veteran Affairs Diabetes Feasibility Trial. Veterans Affairs Cooperative Study on glycemic control and complications in type 2 diabetes (VA CSDM). Arch Intern Med 157: 181-188

62. UK Prospective Diabetes Study (UKPDS) Group (1998) Intensive blood glucose control with sulphonylureas or insulin compared with conventional treatment and risk of complications in patients with type 2 diabetes (UKPDS 33). Lancet 352: 837-853

63. UK Prospective Diabetes Study (UKPDS) Group (1998) Effect of intensive blood glucose control with metformin on complications in overweight patients with type 2 diabetes. (UKPDS 34). Lancet 352: 854-865

64. American Diabetes Association (2001) Postprandial blood glucose. Consensus Statement. Diabetes Care 24: 775-778

65. Diabetes Control and Complications Trial Research Group (1993) The effect of intensive treatment of diabetes on the development and progression of long-term complications in insulin-dependent diabetes mellitus. N Engl J Med 329: 977-986

66. Shichiri M, Kishikawa H, Ohkubo Y, Wake N (2000) Long term results of the Kumamoto Study on optimal diabetes control in type 2 diabetic patients. Diabetes Care 23 [Suppl 2]: B21-B29

67. Malmberg K for the DIGAMI Study Group (1997) Prospective randomised study of intensive insulin treatment on long term survival after acute myocardial infarction in patients with diabetes mellitus. BMJ 314: 1512-1515

68. European Diabetes Policy Group (1999) A desktop guide to type 2 diabetes mellitus. Diabet Med 16: 716-730

69. Horton ES, Clinkingbeard C, Gatlin M, Foley J, Mallows S, Shen S (2000) Nateglinide alone and in combination with metformin inproves glycemic control by reducing mealtime glucose levels in type 2 diabetes. Diabetes Care 23: $1660-1665$

70. Wolffenbuttel BHR, Landgraf R on behalf of the Dutch and German Repaglinide Study Group (1999) A 1-year multicenter randomized double-blind comparison of repaglinide and glyburide for the treatment of type 2 diabetes. Diabetes Care 22: 463-467 